\title{
Optimization of the naphtha hydro treating unit (NHT) in order to increase feed in the refinery
}

\author{
Amir Samimia, Soroush Zarinabadib,*, Amir Hossein Shahbazi Kootenaeia, \\ Alireza Azimia, Masoumeh Mirzaeia \\ a Department of Chemical Engineering, Mahshahr Branch, Islamic Azad University, Mahshahr, Iran \\ ${ }^{b}$ Department of Engineering, Ahvaz Branch, Islamic Azad University, Ahvaz, Iran
}

Received: 13 October 2019, Accepted: 02 November 2019, Published: 23 November 2019

\begin{abstract}
Increasing the capacity of this unit will cause problems such as the increase of pressure downfall, reduction of output pressure of circulating gas compressor, the increase of the eventuality of coke formation on the catalyst, increasing the thermal load of the reboiler furnaces of unit towers and eventually reducing the catalyst life span. In this research, operating conditions have been investigated that indicates the increase of the refinery feed with the design capacity of 50,000 barrels per day, to the amount of 55,000 barrels per day. The results indicate that with increasing feed, the entrance temperature of the unit reactor should be increased. At the same time, the temperature increase caused the increasing of coke formation on the catalyst and rising the difference of entrance and output pressure of the reactor. Also, the thermal load of the furnaces of stripper and splitter towers increased. In this paper, with the modeling of the catalyst inactivation at the slightly temperature, as well as the troubleshooting of the system afterward, with regards to all the above conditions, it is proved that increasing the feed is an acceptable action according to the resulting profit from the sale of the products.
\end{abstract}

Keywords: Reactor; coke; stripper; modeling; splitter; catalyst.

\section{Introduction}

The deletion of impurity of petrol fuels, especially sulfur, is becoming important day by day. The impurities of all kinds of light and heavy petrol cuts can be removed with hydrogen in the proximity of the suitable catalyst. These impurities include sulfur, nitrogen, oxygen compounds, and metals. The purification methods with hydrogen have great importance in the refining of petroleum products [1, 2, and 3]. By creation of naphtha purification units and preparation of hydrogen as the by- product with cheap price and the deletion of impurities with hydrogen gradually developed till today, the fewer refineries can be found that lack the process of deletion impurities of petroleum products by hydrogen. Different activities have been carried out in the optimization field of purification units of petrol cuts by hydrogen [4-6].

\section{The purification process with} hydrogen

There are some nitrogenous, oxygenated, sulfur compounds and 
unsaturated compounds in the petrol cuts and petroleum that can have an important role in the pollution of the environment, catalysts poisoning and equipment corrosion. The purpose of the purification operation by hydrogen is to eliminate or decrease these pesky compounds. In purification operations with hydrogen, the reactions of desulfurization, nitrogenization, deoxygenating, the metals and halogens reduction, and hydrogenation are performing [2-4]. The main feature of these reactions is the rupture of the $\mathrm{C}-\mathrm{S}$, $\mathrm{C}-\mathrm{N}$ and $\mathrm{C}-\mathrm{O}$ bonds in the presence of hydrogen that results in separating $\mathrm{S}, \mathrm{N}$, and $\mathrm{O}$ from hydrocarbons and converting them to $\mathrm{H}_{2} \mathrm{~S}, \mathrm{NH}_{3}$, and $\mathrm{H}_{2} \mathrm{O}$ [1-3].

Of course, concurrent with these reactions, the hydrocracking reaction is also carried out laterally [1-3]. The purification processes of hydrogen are usually similar, but the operating conditions are different considering the type of feed. The consumable catalyst of these processes is Molybdenum-Cobalt or Molybdenum-Nickel based on gamma alumina. These processes usually include two parts:

1. Reaction section (reactor)

2. Separation section

The purification operations can be done by returning the productive gases or without returning productive gases.

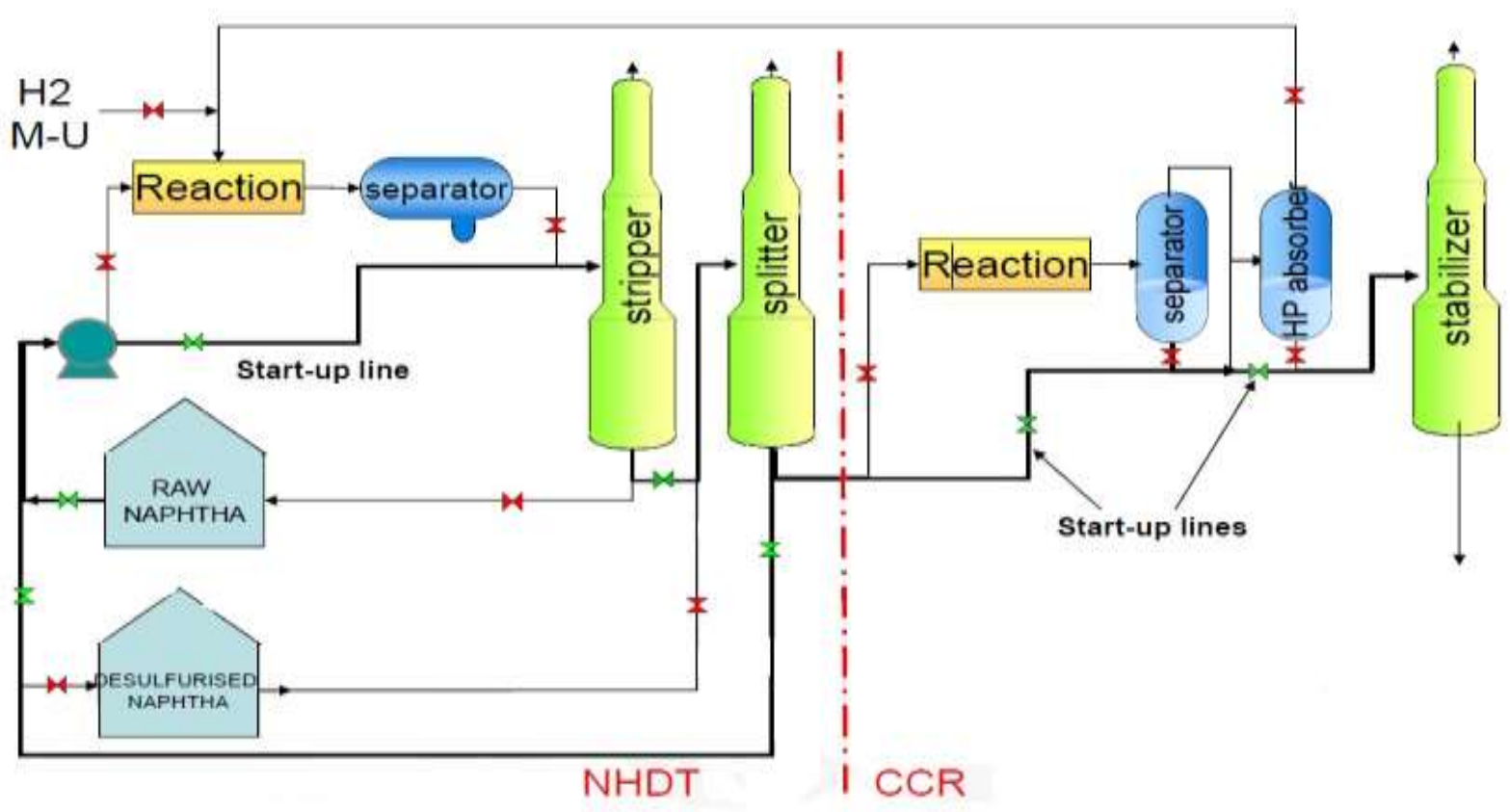

Figure 1. The schema of the hydrogenous purification unit

The description of the naphtha purification process

In the process of naphtha purification, Light naphtha should be used for the process with the returned gas because the amount of sulfur in the feed is high (700-1200 wt ppm) [7]. Of course, in this mood, the gas may be washed with the amine. The existent sulfur and nitrogen in the feed are converted to $\mathrm{H}_{2} \mathrm{~S}$ and $\mathrm{NH}_{3}$ after passing through the catalyst bed and in the hydrogen adjacency. The naphtha purification unit is designed for a certain rate of feed along with the highest level of sulfur, nitrogen, mercury, arsenic and other materials in the petroleum. If the quality of the feed changes due to the change in 
the quality of the processed petroleum and the higher rate of sulfur and nitrogen enters into the system, it is necessary to increase the beneficiary of the reactor entrance temperature. For the new petroleum, the obtained naphtha feed from it should be tested in terms of all impurities, including metals [8-13]. If possible, this doing should be done before the injection of the feed into the unit, but otherwise, it is necessary to be done as soon as possible. This work prevents the fast saturating of the catalyst due to the entry of more metals. The feed with higher boiling point doesn't specifically affect the performance of the catalyst $\left(20{ }^{\circ} \mathrm{C}\right)$ except that it is causing more coke to sit on the catalyst and shorten its life span. After mixing with fresh hydrogen and the returned hydrogen (a purity of about 90 volume percent) and passing through the thermal exchanger and furnace, the process feed (heavy naphtha) temperature increased to ranges from 260 to $320{ }^{\circ} \mathrm{C}$ (the amount of temperature depends on the catalyst lifetime or the intensity of desulphurization). The heated feed enters into the catalytic reactor after passing through the furnace [14-18]. The reactor product enters into separator with high-pressure after the thermal exchange with the entrance feed as well as chilling by the aerial cooler and increasing a certain amount of supplementary hydrogen. Hydrogen along with light gases and hydrogen sulfide is exited from the upper part of the separator. The major part of this gas is returned to entrance feed in the processes that are operating with the returned gas system. The output liquid from the separator also enters the stripper tower. The condenser of this tower is the total reflux type. Ultimately, the light gases and remaining sulfur are exiting as hydrogen sulfide gas from above the tower. The refined product is also exited after the exchange of heat with the entrance feed with water contents of less than 1 , the weighted ppm and sulfurous and nitrogenous compounds with the content of less than 0.5 , and the weighted ppm from the end of the tower. Then, it is guided toward the naphtha purification unit. The reactor of this process is from the fixed bed type and usually, the feed flow in the interior of them is from the top to bottom, but sometimes it is used from the flow of bottom to high for the mixture of liquid and gas [19-21].

\section{The system troubleshooting}

The main concern in this part is the passing of sulfur from the naphtha purification unit and the entrance of it into Octanizer and isomerization units. One of the most fundamental proceedings is the consignation of the separator and stripper towers' products toward the reservoirs. In this mood, the feed of the reformer and isomerization units is provided through reservoirs. The beneficiary should ensure that the existent feed in the reservoirs and its linked routes are without water. In the absence of certainty, it is recommended that the feed of the reformer unit be reduced, or even the downstream units are removed from the service [22-26].

\section{Probabilistic problems include}

Increasing the existent sulfur in the terminal product of the stripper tower 0.5-1 ppm

The temperature of the bottom of the stripper tower and also the amount of the returned flow to the tower was given the increase. The existent sulfur in the terminal product was given the test again. Sulfur was tested again without any change; the reactor was given an increase of temperature up to another 5 ${ }^{\circ} \mathrm{C}$. In this state, if the amount of sulfur was high again, the feed to be given 
decrease up to $60 \%$ of the design capacity and the test should be done again. In the end, if the amount of sulfur was still high, the feed transmission to the isomerization and reformer units should be disconnected and be provided from the reservoirs. Here, it is imperative to ensure that there isn't water in the feed reservoirs and the related routes.

The Existence of numerous nitrogen in the terminal product of the stripper tower

This case is the subordinate of the existent nitrogen in the feed and also the reactor temperature [27-30]. The rate of existent nitrogen in the feed is investigated. The reactor temperature is given the increase to the amount $5{ }^{\circ} \mathrm{C}$ as long as the problem is resolved.

The downfall of the high-pressure in the reactor

The unit design is in such a way through which the highest downfall of pressure is possible. The unit design with the downfall of the high-pressure makes possible the naphtha purification alternately. The existence of the reactor pressure downfall indicator in the control room and the obtained data from it gives the possibility to the operator to predict the time of closing the unit and replacement of the upper part of the catalyst [31-35].

The Existence of Leaky in the feed/product converters or terminal product

Since the feed pressure is higher in both cases, there is the eventuality of the sulfur leak through the feed to the product or terminal product. When the sulfur is seen at the terminal product of the stripper tower, we can send product to splitter.

Emergency block of the unit if problems eventuate from the reduction or discontinuation of the feed
The shortage or lack of sufficient feed in the unit can be due to the happened problems in the feeder pump, while the spare pump has also started its work with an unusual delay. Often, it also resulted from other problems such as leakage, etc. that happens in the feed pipeline and is disconnected in order to repair the feeder line. Due to the abundant hoarding accumulated in the feed surge drum, feed stopping from the unit boundary isn't so problematic. Although it is necessary for the operator to pay attention to the hold-up volume and the time at its disposal and dispels, the problem of stopping the feeder pump is resolved as soon as possible [36]. Loss of feed is more acute due to the problem in the feed pump. The residue of the splitter tower and the existent hoarding in the reflux container provide the appropriate opportunity for feed preservation of the ISO, CCR units. The entrance temperature of the reactor is set in $250{ }^{\circ} \mathrm{C}$ and the circulation circuit of the $\mathrm{H}_{2}$ gas is maintained [37-41]. When the liquid surface of the separator container starts to decrease, it cuts off the feed of stripper tower and closes its FCV. When the liquid surface of the stripper container also starts to decrease, the bottom exit of the tower that it's toward the splitter is to be closed and its FCV is to be blocked. When the liquid surface of the splitter tower starts to decrease, the product pump of H.N is to be stopped and when the liquid level of the reflux container also starts to decrease, the L.N pump is to be stopped. The splitter and stripper towers are to be placed in the full reflux conditions and the feed paths of ISO and CCR units are to be blocked. These conditions should be maintained until the renewed establishment of the feed and the pressure of the reaction section and the stripper with compensatory hydrogen are accomplished [42-46]. 
Emergency block of the unit while the problem is from the boiler of the stripper tower or the re-boiler pump

This problem is returning to the respective furnace or pump, of course, when the reboot of the spare pump is not done automatically. In these conditions, the following actions will be done. The feed disconnection to the splitter tower will be done quickly, and also be led the bottom path of stripper tower to the crude naphtha reservoirs because naphtha along with $\mathrm{H}_{2} \mathrm{~S}$ shouldn't be sent to ISO and CCR units. The naphtha's feed is disconnected completely because naphtha containing $\mathrm{H}_{2} \mathrm{~S}$ shouldn't be sent to reservoirs. The reflux pump of the stripper tower should be exited from the service and the pressure of the stripper tower be provided with fuel gas.

The emergency block of the unit due to the problem in the reflux of stripper tower

This issue is related to the time that the reflux pump of stripper tower has a deficiency and the spare pump isn't placed automatically on the service. Keeping the quality of the bottom product of the tower is difficult without having a reflux current in the stripper tower. In such circumstances, it is necessary to do the following actions. Quickly, the unit capacity needs to be decreased to $60 \%$ of design and the residue of the stripper tower be sent to the crude naphtha reservoir. The temperature of the bottom of the stripper tower should be reduced until the returned flow (reflux) is reduced to the possible minimum. The contents of the reflux container should be directed toward the flare. The consignor pumps of the light and heavy naphtha products should be exited from service and the splitter tower should be placed in a total reflux mode. If there isn't the possibility of total reflux for a long time, the flow path in the reactor and its supplements (Reaction) should be changed toward bypass start-up or the feed is interrupted.

The emergency block of the unit due to the problem in the reflux of splitter tower

This issue is related to the time that the reflux pump of splitter tower has a deficiency and the spare pump isn't placed automatically on the service. Keeping the quality of the products and the adjustment of the features of light, semi-heavy, and heavy naphtha is difficult without having the reflux current in the splitter tower. In such circumstances, it is necessary to do the following actions. The feeder routes to the downstream units should be disconnected and also the corresponding control valves should be blocked. The feed of the hydrogenous purification unit (hydrotreater) needs to be reduced to $60 \%$ of the design capacity, and the bottom, middle and upper outlets of the tower should be sent to the Cold Slops. The rate of furnace fuel should be reduced until the production of overhead products is reduced, but the pressure of the tower should be maintained. If the reflux pumps aren't working as well as for a long time, the residue path of the stripper tower should be directed to the crude naphtha reservoirs, the furnace fuel of splitter tower should be disconnected, and all of the consignor pumps of the light, semi-heavy and heavy naphtha should be exited from service and the pressure of the tower should be maintained with nitrogen gas.

\section{The Model of the becoming deactivation of the catalyst at constant temperature and output constant octane}

If $t$ (a) is considered as the rate of catalyst activity at time $\mathrm{t}$

$$
a(t)=\frac{r_{a}(t)}{r_{a}(0)}
$$


In this equation, $r_{a}(t)$ is the reaction speed at time $t$ and $r_{a}(0)$ is the reaction speed at the start of the reaction with the fresh catalyst $(\mathrm{a}=1)$. If the total speed of the reaction is considered at the form of the multiplication of the three sentences, the first contains the temperature dependence, the second representing the catalyst activity drop and the third is the concentration dependence according to the conversion degree $\left(\mathrm{X}_{\mathrm{a}}\right)$, because the temperature is constant, we have:

$r_{a}=-k_{0} \exp \left[\frac{-E_{A}}{R T}\right] a f\left(X_{A}\right)=-k^{\prime} a f\left(x_{A}\right)$

We use the following equation for illustration of the becoming deactivation rate of the catalyst:

$-\frac{d_{a}}{d_{t}}=k_{d 0} \exp \left[\frac{-E_{D}}{R T}\right] g\left(X_{A}\right) a^{n}$

In this equation, $\mathrm{k}_{\mathrm{d} 0}$ and $\mathrm{E}_{\mathrm{D}}$ are the constant parameters of the becoming deactivation rate and $g\left(X_{\mathrm{A}}\right)$ representing the concentration dependence in the activity rate equation and $\mathrm{n}$ is the degree of the becoming deactivation rate. At constant temperature and constant conversion rate, the becoming deactivation equation is summarized as follows:

$$
-\frac{d_{a}}{d_{t}}=k_{d 0} \exp \left[\frac{-E_{D}}{R T}\right] g\left(X_{A}\right) a^{n}=k_{d}^{\prime} a^{n}
$$

\section{Temperature changes with catalyst lifetime}

Industrial units, usually in order to compensate for the catalyst activity decline, try to control the quality of the product with increasing the temperature of the entrance feed instead of reducing the passing rate of the feed from the catalyst (LHSV) because reducing the amount of the product in order to control its quality isn't desirable and economical. Thus, one process of increasing temperature in the production process is observed simultaneously with the decrease of catalyst activity. Increasing the rate of temperature is faced with limitations that determine the lifetime of the catalyst, including the thermic limitation of the reactor and the involved equipment in the process, changing the catalyst base construction, changing the distribution way of active elements on the catalyst (sintering), and also the high cost of the temperature supplying. Ending the catalyst life period, depending on the type of catalyst, the rate of price and also the possibility of revival, take action to its replacement or revival [47]. The following equation expresses the reality of the need to the temperature increase in order to compensation for the catalyst activity drop by connecting the catalyst activity to the function from the operating temperature. The conditions required for using the below equation are the product constant quality (constant conversion) and also being constant the feed rate (LHSV). This Quality is resulted from the equation (2) in constant conversion [1]:

$k(T) a(t)=k\left(T_{0}\right)$

Wherein $\mathrm{T}_{0}$ is the used absolute temperature at the beginning of the utilization of the catalyst and $\mathrm{T}$ is the temperature to be used at time $t$ till it compensates the catalyst activity drop with the speed constant increase. By placing the equivalent of the temperature function from equation 2 , the above equation is as follows [48]:

$$
a(t) \exp \left[\frac{-E_{A}}{R T}\right]=\exp \left[\frac{-E_{A}}{R T_{0}}\right]
$$




$$
\begin{aligned}
& a(t)=\exp \left[\frac{-E_{A}}{R}\left(\frac{1}{T_{0}}-\frac{1}{T}\right)\right] \\
& \frac{1}{T}=\frac{R}{E_{A}} \ln a+\frac{1}{T_{0}} \\
& -\frac{d_{a}}{d_{t}}=k_{d 0} \exp \left[\frac{-E_{D}}{R}\left(\frac{R}{E_{A}} \ln a+\frac{1}{T_{0}}\right)\right] a^{n}=k_{d o} \exp \left[\frac{-E_{D}}{R T_{0}}\right] a^{n-\frac{E_{D}}{E_{A}}} \\
& -\frac{d_{a}}{d_{t}}=k_{d 0} \exp \left[\frac{-E_{D}}{R T}\right] g\left(X_{A}\right) a^{n}=k_{d}^{\prime} a^{n}
\end{aligned}
$$
have:

$$
t=\frac{\left.E_{A}\left\{1-\exp \left[\frac{E_{D}-n E_{A}+E_{A}}{R \cdot\left[\frac{1}{T}-\frac{1}{T_{o}}\right]}\right]\right]\right\}}{k_{d 0} \exp \left[\frac{-E_{D}}{R T_{0}}\right] \cdot\left[E_{D}-n E_{A}+E_{A}\right]}
$$

To summarize the above equation, we use two parameters $\mathrm{B}, \mathrm{A}$, which are defined as follows:

$$
\begin{aligned}
& t=A\left[1-\exp \left(B\left(\frac{1}{T}-\frac{1}{T_{0}}\right)\right)\right] \\
& A=\frac{\frac{E_{A}}{\left(E_{D}-n E_{A}+E_{A}\right)}}{k_{d 0}} \\
& B=\frac{E_{D}-n E_{A}+E_{A}}{R}
\end{aligned}
$$

By solving the equation for operating temperature, we have:

$$
T=\left[\frac{1}{T_{0}}+\frac{1}{B} \ln \left(1-\frac{t}{A}\right]^{-1}\right.
$$

The equation (13) shows the thermic connection $(\mathrm{T})$ which must be used with the passage of time $(\mathrm{t})$ in order to compensate for the catalyst activity drop.

Using the model of becoming deactivation of the catalyst can be used for the model by the equation of 4 for the catalyst activity:

For correspondence of the actual conditions with the above equation in the catalytic conversion unit, the catalyst activity rate proportional with the process feed rate at the constant temperature and also the constant octane of the product at any time is considered to the primary feed of the unit. Of course, in order to obtain the mentioned data, the necessary correction had been done in the actual data according to the existent method in the industry. There are information and graphs between the temperatures. The rate of feed and the octane number according to the experiences of the catalyst builder companies can be observed using the variation effect of each of these variables. In this paper, using these relationships and diagrams, experimental data have been corrected for the matching of the above equation. In this way, it has been ignored from the octane and temperature fluctuations during catalyst servicing time, and the unit is assumed in the constant temperature and octane.

Therefore, the only variable that must be changed for fixing the octane number at constant temperature is the amount of unit feed that the trend of feed changes during the catalyst servicing time (its decrease) is as characteristic of the catalyst activity drop. Thus, by defining the rate of catalyst activity, it can be obtained at any time according to the following equation, consequently, 
we will have the activity data in terms of the time.

$$
a(t)=\frac{\text { feed rate at time e } t}{\text { feed rate at start up }}=\frac{f_{(t)}}{f_{(0)}}
$$

with integrating from equation 4 :

$a=\left[(1-n)\left[-k^{\prime}{ }_{d .} t+c\right]\right]^{\frac{1}{1-n}}$

According to the definition of equation (14) from the catalyst activity, activity according to time (Figure 2), $k_{d}^{\prime}$ and $\mathrm{n}$ of the parameters of equation 15 are obtained:

$\mathrm{n}=4$

$\mathrm{k}_{\mathrm{d}}^{\prime}=1.07 \times 10^{-3} \frac{1}{d a y}$

By drawing the temperature graph according to time (Figure 3 ) in the octane of 94 and the feed of 4000 barrels/ day and the initial temperature $\mathrm{T}_{0}=776^{\circ} \mathrm{K}$ and its conformity with the equation of 13 and also because factors for coke formation are mainly caused by dehydrogenation reactions and the activation energy for this category of reactions is $1.10 \times 62^{\wedge} 5 \mathrm{~J} / \mathrm{mol}$, the values of $E_{D}, k_{d 0}$ are obtained [49-51].

$E_{D}=1.38 \times 10^{6} \mathrm{j} / \mathrm{mol}$

$\mathrm{K}_{\mathrm{d} 0}=2.45 \times 10^{-4} 1 /$ day

\section{Application of the model for determining the life period of the catalyst}

According to the accuracy of equation 13 in the estimation of the variations of the process temperature with the function time of the catalyst, as can be seen from the adaptation of the equation with empirical data in Figure (3), with exerting the obtained parameters, it can be used to determine the life of the catalyst.

Therefore, if the ordinary conditions of the process are dominated, using this model can obtain the maximum of the catalyst operating time in the constant octane of 94 and the constant feed of 4000 barrels per day. The time of the becoming deactivation of the catalyst is the same maximum of the catalyst function time which can be predicted that it's for deciding about the revival or replacement of the catalyst.

\section{Results and discussion}

Regarding the modeling and the review of the obtained results, it can be observed that the amount of pressure drop in the thermal inverters is decreased significantly and the pressure is increased in the high-pressure separator container and at the entrance compressor of the cyclical gas.

Therefore, the compressor can be adjusted to the output pressure and the amount of cyclical gas flow (the ratio amount of hydrogen to hydrocarbon in the reactor) in the appropriate values. Also, the amount of thermal load will become more in the boiler of the stripper tower. The amounts of hydrogen sulfide, ammonia, and water haven't so changed in the output of the unit. Economically, also, this plan didn't have much-fixed cost.

Table 1. Comparison of the purity state of the stripper tower feed flow

\begin{tabular}{ccc}
\hline $\begin{array}{c}\text { Condition Before } \\
\text { Increasing Feed }\end{array}$ & $\begin{array}{c}\text { Condition After } \\
\text { Increasing Feed }\end{array}$ & $\begin{array}{c}\text { Variable Point } \\
\text { ppm }\end{array}$ \\
\hline 212 & 208 & $\mathrm{H}_{2} \mathrm{~S}$ \\
0.509 & 0.522 & $\mathrm{NH}_{3}$ \\
\hline
\end{tabular}

Table 2. Comparison of the Purity state of the Stripper Tower's Product

\begin{tabular}{ccc}
\hline Condition Before & Condition After & Variable Point \\
Increasing Feed & Increasing Feed & ppm \\
\hline
\end{tabular}




\begin{tabular}{lll}
\hline Minimum & Minimum & $\mathrm{H}_{2} \mathrm{~S}$ \\
Minimum & Minimum & $\mathrm{NH}_{3}$ \\
\hline
\end{tabular}

Investigating the affection of changes of the unit capacity on the octane number of gasoline and the amount of the formed coke on the catalyst

The conditions of the entrance constant temperature to the reactor which equals to $290{ }^{\circ} \mathrm{C}$ and the rate of the mass flow's constant of the returned hydrogen gas equivalent to $450 \mathrm{~kg} / \mathrm{hr}$ with the purity of $90 \%$ are investigated. The rate of octane number of productive gasoline and the amount of the percentage of the formed coke on the catalyst surface are also dependent variables. The permissible range of the amount of the percentage of the formed coke on the catalyst surface based on the capacity of the catalyst revival coke fire unit is (3-6) $\%$. This range also is the limiting factor in operating conditions. It can be concluded that by increasing unit capacity, the octane number of the gasoline product decreases and the amount of the percentage of the formed coke on the unit catalyst surface increases. In these changes of the unit capacity, the amount of the percentage of the formed coke is placed in the permitted range [52].

Table 3. Resultant values from the affection of change of the naphtha purification unit capacity on the octane number of gasoline and the amount of the percentage of coke formation on the catalyst

\begin{tabular}{ccc}
\hline Coke formation \% & Octane NO. & $\begin{array}{c}\text { Capacity } \\
\text { B/Day }\end{array}$ \\
\hline 3.65 & 95 & 44000 \\
3.7 & 94.8 & 45000 \\
3.77 & 94.7 & 46000 \\
3.79 & 94.6 & 47000 \\
3.80 & 94.4 & 48000 \\
3.88 & 94.1 & 52000 \\
3.90 & 94 & 53000 \\
3.95 & 93.9 & 55000 \\
\hline
\end{tabular}

Investigating the affection of entrance temperature of the reactors of the naphtha purification unit on the octane number of gasoline and the amount of the formed coke on the catalyst

Due to the importance of the entrance temperature to the reactor, the sensitivity analysis was carried out on the entrance temperature change of the reactor on the octane number and the rate of coke production. This mode is in the condition of the constant capacity which equals to $55000 \mathrm{~b} /$ day of naphtha feed and the rate of the mass flow's constant of the returned hydrogen gas equivalent to $450 \mathrm{~kg} / \mathrm{hr}$ with the purity of $90 \%$ is investigated. Also, the entrance temperature of reactors, which is one of the most important affecting factors on the octane number, is considered as the independent variable and the octane number of gasoline product and the amount of the percentage of the formed coke on the catalyst surface is considered as the dependent variable. As the reactor temperature increases, the octane number of the gasoline increases but, the amount of the formed coke also increases due to increasing the reactor temperature. The slope of this coke formation from the temperature of 300 ${ }^{\circ} \mathrm{C}$ is increasing remarkably, which this increase manner was problematic and is the limiting factor of the possibility of the temperature increase. 
Presenting how the adjustment of the reactors entrance temperature and catalyst circulation rate at different capacities such that the octane number is the constant amount of 95 and the amount of the percentage of coke formation is the constant of $3.5 \%$ in all conditions.

Due to the adjustments and limitations of the coke fire unit and the catalyst revival, the percentage of the formed coke must also be fixed. The constant condition of this scenario is the percentage of the formed coke which equals to $3.5 \%$ and the octane number of the gasoline's produce should be 95 . The rate of the mass flow's constant of the returned hydrogen gas equivalent to 450 $\mathrm{kg} / \mathrm{hr}$ with the purity of $90 \%$ is investigated.

Table 4. Numerical values of entrance temperature changes of the reactors of the naphtha purification unit on the octane number of gasoline and the amount of the percentage of the formed coke on the

\begin{tabular}{ccc}
\multicolumn{3}{c}{ catalyst } \\
\hline Coke formation & Octane No & $\begin{array}{c}\text { Temperature } \\
\left({ }^{\circ} \mathbf{C}\right)\end{array}$ \\
\hline 2.726 & 59 & 280 \\
2.733 & 60 & 281 \\
2.740 & 62 & 282 \\
2.749 & 63 & 283 \\
2.760 & 65 & 284 \\
2.773 & 67 & 285 \\
2.788 & 68 & 286 \\
2.806 & 71 & 287 \\
2.826 & 73 & 288 \\
2.825 & 76 & 289 \\
2.882 & 78 & 290 \\
2.914 & 80 & 291 \\
2.950 & 83 & 292 \\
2.990 & 85 & 293 \\
3.030 & 88 & 294 \\
3.091 & 90 & 295 \\
3.167 & 92 & 296 \\
3.261 & 94 & 297 \\
3.384 & 95 & 298 \\
3.536 & 97 & 299 \\
3.738 & 98 & 300 \\
\hline
\end{tabular}

\section{Conclusion}

Sulfur, nitrogenous, oxygenated compounds, existent unsaturated compounds and metals, and petroleum compounds are some of the main factors of environmental pollution, catalyst poisoning, and equipment corrosion. The naphtha purification process is one of the processes of hydrogenous purification in petrochemical complexes and refineries that by removing sulfur, nitrogen, oxygen, metals, and halogens from the entrance of heavy naphtha feed to the catalytic conversion unit. In addition to protecting the catalyst from toxins and the precocious becoming deactivation, it makes possible the production of gasoline with the least pollutants of the environment. In this research, increasing the capacity of the naphtha purification unit of one of the country's refineries from 12,000 barrels to 15,000 barrels per day without the outbreak of problems such as increasing the pressure drop in the aerial and evaporative coolers in the separation part, reducing the exhaust pressure of the cyclical gas compressor and 
reducing the catalyst life, had been investigated [53].

\section{Acknowledgements}

The work presented in this paper is part of a research project (Ph.D.) of Amir Samimi in Islamic Azad University of Mahshahr, I.R.Iran.

\section{References}

[1] S. Ghani, W.A. Jada, $J$. Thermodynamics \& Catalysis, 2012, 3, 1-6.

[2]. S. Janitza., G. Tutz., A. Boulesteix., Comput. Stat. Data Anal., 2016, 2, 5773.

[3] A.M. Imran, N. Zhang, M. Jobson, Chemical Engineering Research and Design, 2011, 89, 1025-103.

[4] S. Sedighi, S.R. Mohaddesi, Applied researches in chemistry, 2013, 7, 5-12.

[5] S. Mederos, J. Ancheyta, I. Elizalde., Applied Catalysis A, 2012, 425, 13-27.

[6] C. Popa, Procedia Engineering, 2014, 69, 1469-1474.

[7] A.V. Spare, Chemical Engineering Science, 1997, 52, 4615-4623.

[8] J.W. Lee, Y.C. Ko, Y.K. Jung, K.S. Lee, Computers chem..Engng, 1997, 21, 105- 110.

[9] S. Arlot, A. Celisse, Stat. Surv., 2010, 4, 40-79.

[10] M. Gerdes, Master's thesis. Linköping University, Fluid and Mechatronic Systems, the Institute of Technology, 2017, 11-42.

[11] G.U. Shankru., K. Vijayakumar., V. Umadevi, Future Computing and Informatics Journal, 2018, 2, 210-224.

[12] G. Xiaoyong., H. Dexian., J. Yongheng., T. Chen., Chinese Journal of Chemical Engineering, 2018, 26, 1605-1612.

[13] A. Anatolevich, S. Michailovich, Chemical Methodologies, 2019, 1, 1-14. [14] S. Houshmandynia, R. Raked, F. Golbabaei, Chemical Methodologies, 2018, 4, 270-340.
[15] H. Shafiee, F. Mostaghni, K. Ejraei, Chemical Methodologies, 2018, 2, 83180.

[16] O. Ghasemi, N. Mehrdadi, M. Baghdadi, B. Aminzadeh, Iran. Chem. Commun., 2019, 4, 352-367.

[17] G. Mansouri, M. Ghobadi, Iran. Chem. Commun., 2019, 4, 424-431.

[18] E. Mazloumi, G. Rose, G. Currie, S. Moridpour., Eng. Appl. Artif. Intell., 2011, 2, 534-542.

[19] (a) S. Mohammadi, A. Taheri, Z. Rezayati-zad, Prog. Chem. Biochem. Res., 2018, 1, 1-10; (b) S. Sajjadifar, Z. Arzehgar, A. Ghayuri, Journal of the Chinese Chemical Society, 2018, 65, 205-211.

[20] S. Aline., L. Eduardo, A. Felipe de A. Mello Pereira, Information Processing Letters, 2017, 127, 27-31

[21] T. Varga, F. Szeifert, J. Abonyi, Eng. Appl. Artif. Intell., 2009, 5, 569578.

[22] T. Madhar, Journal of Safety Research, 2018, 66, 121-129

[23] H. OH, W.S. SEO, Japan Journal of Nursing Science., 2012, 5, 110-121

[24] S. Sohn, J. Kim, Expert Systems with Applications, 2012, 39, 4007-4012. [25] M. Gyngazova, A.V. Kravtsor, E.D. Ivanchina, M.R. Korolenko, D.D. Uvarkina,Catalysis in Industry, 2010, 2, 117-128.

[26] H. Weifeng, S. Hongye, M.U. Shengjing, CHU. Jian, Chinese Journal of Chemical Engineering, 2007, 15, 7580

[27] T. Gueddar, D. Vivek, Computer \& Chemical Engineering, 2011, 35, 18381856.

[28] M.S. Gyngazova, N.V. Chekantsev, M.V. Korolenko, E.D. Ivanchina, A.V. Kravtsov, Catalysis in Industry, 2012, 4, 284-291.

[29] D. Iranshah, M. Karimi, S. Amiri, M. Jafari, R. Rafiei, M. Rahimpour, Chemical Engineering Research and Design, 2014, 9, 1704-1727. 
[30] M.Z. Stijepovic, A.V. Ostojic, I. Milenkovic, P. Linke, Energy \& Fuel Journal, 2009, 23, 979-983

[31] H. Arani, M. Shirvani, K. Safdarian, E. Dorostkar, Journal Chemical Engineering, 2009, 26, 723732

[32] R.E. Palmer, S.H. Kao, C. Tong, D.R. Shipman, Hydrocarbon processing., 2008, 5, 55-66

[33] S.M. Habibi-Khorassani, M. Dehdab, M. Darijani, Iran. Chem. Commun., 2019, 4, 455-471

[34] F. Fayyaz Jorshari, M. Rabbani, R. Rahimi, M. Rassa, Iran. Chem. Commun., 2019, 1, 53-62

[35] R. Motamedi, F. Ebrahimi, G. Rezanejade Bardajee, Asian J. Green Chem., 2019, 3, 22-33.

[36] S. Sajjadifar, I. Amini, H. Jabbari, O. Pouralimardan, M.H. Fekri, K. Pal, Iran. Chem. Commun., 2019, 7, 191199.

[37] A. Hassankhani, Iran. Chem. Commun., 2019, 7, 248-256.

[38] H. Hasani, M.Irizeh, Asian J. Green Chem., 2018, 2, 85-95.

[39] L. Nagarapu, M. Baseeruddin, S. Apuri, S. Kantevari, Catal. Commun., 2007, 8, 1729-1734.

[40] M. Lei, L. Ma, L. Hu, Tetrahedron Lett., 2009, 50, 6393-6397.

[41] S. Sheik Mansoor, K. Aswin, K. Logaiya, S.P.N. Sudhan, J. Saudi Chem. Soc., 2016, 20, 138-150.

[42] (a) M. Kooti, M. Karimi, E. Nasiri, J. Nanopart. Res., 2018, 20, Art. No. 16; (b) Z. Arzehgar, S. Sajjadifar, H. Arandiyan, Asian J. Green Chem., 2019, $3,43-52$.
[43] S. Ameli, A. Davoodnia, M. Pordel, Org. Prep. Proced. Int., 2016, 48, 328336.

[44] M. Fattahi, A. Davoodnia, M. Pordel, Russ. J. Gen. Chem., 2017, 87, 863-867.

[45] A. Nakhaei, A. Davoodnia, S. Yadegarian, Iran. Chem. Commun., 2018, 6, 334-345.

[46] E. Teymooria, A. Davoodnia, A. Khojastehnezhad, N. Hosseininasab, Iran. Chem. Commun., 2019, 7, 271282.

[47] (a) A.N. Egorochkin, O.V. Kuznetsova, N.M. Khamaletdinova, L.G. Domratcheva-Lvova, Inorganica Chim. Acta, 2018, 471, 148-158; (b) S. Sajjadifar, Chemical Methodologies, 2017, 1, 1-11.

[48] H. Anane, S.E. Houssame, A.E. Guerraze, A. Guermoune, A. Boutalib, A. Jarid, I. Nebot-Gil, F. Tomás, Cent. Eur. J. Chem., 2008, 6, 400-403.

[49] M.H. Fekri, A. Omrani, S. Jamehbozorgi, M. Razavi mehr, Advanced Journal of Chemistry-Section A, 2019, 2, 14-20.

[50] H. Szatylowicz, A. Jezuita, T.Siodła, K.S. Varaksin, M.A. Domanski, K. Ejsmont, T.M. Krygowski, ACS Omega, 2017, 2, 71637171.

[51] R. Ghiasi, A.zamani, J. Chin. Chem. Soc., 2017, 64, 1340-1346.

[52] R. Ghiasi, H. Pasdar, S. Fereidoni, Russian J. Inorg. Chem., 2016, 61, 327333.

[53] R. Ghiasi, A. Heydarbeighi, Russian J. Inorg. Chem., 2016, 61, 985992.

How to cite this manuscript: Amir Samimi, Soroush Zarinabadi, Amir Hossein Shahbazi Kootenai, Alireza Azimi, Masoumeh Mirzaei. Optimization of the naphtha hydro treating unit (NHT) in order to increase feed in the refinery. Eurasian Chemical Communications, 2020, 2(1), 150-161. 